\title{
Shape of a crack growth front under fatigue in the range of $10^{6}$ - $10^{7}$ cycles
}

\author{
Georgi Georgiev ${ }^{1}$ \\ 1 - PhD student, Technical University of Varna, Department of Material Science and Technologies, 9010, 1 Studentska Street, Varna, Bul- \\ garia \\ Corresponding author contact: gogo28@abv.bg
}

\begin{abstract}
The paper explores the shape of a fatigue crack initiation in the interval of $10^{6}-10^{7}$ cycles of duplex stainless steel, commercially designated as SAF 2507. Particular emphasis is placed upon the development of the crack's growth front and its subsequent expansion in three directions $x, y, z$ Created, accordingly, on the basis of the experimentally obtained results, is a 3D computer model to help provide a further prediction for the physical endurance of similar materials. The growth of a fatigue crack is modeled by using The SolidWorks and AutoCAD software tools for constructing the model of fatigue crack growth.
\end{abstract}

Keywords: shape of fatigue crack, duplex Stainless Steel, SAF 2507, crack initiation, microstructure

\section{Introduction}

Duplex steels are durable corrosion resistant steels. Used in the chemical industry and in a number of other sectors. Duplex steel SAF 2507, is a Sandvik-owned trademark for a duplex (ferritic-austenitic) stainless steel, with a chemical composition of 25\% Chromium, 7\% Nickel, 4\% Molybdenum and other alloying elements such as Nitrogen and Manganese. The UNS designation for SAF 2507 is S32750 and the EN steel No. is 1.4410. SAF designation derives from Sandvik Austenite Ferrite- a class of stainless steel characterized by a very good chloride corrosion resistance, combined with a very high mechanical strength. Duplex steel SAF 2507 is used in aggressive environments such as warm chlorinated seawater and acidic, chloride containing media. It is extensively used in offshore oil and gas exploration and production and in heat exchangers in petrochemical and chemical processing. The grade is also considered especially suitable for hydraulic and instrumentation applications in tropical marine environments.(Nicholls M., 1993) As regards the visible path of the crack propagation in SAF2507, the microcracks can be described as intergranular, propagating along the primary and sub-grainboundaries, and transgranular, propagating through the interior of the grains. Generally speaking, transgranular cracks appeared more dominant and longer in length. Given the larger crack size and angle of crack propagation, a fracture is likely to occur across the austenite or ferrite grain. Intergranular cracks appeared smaller in size, while its crack propagation appeared to trace the sub-grain boundaries of the ferrite grains, whch is characteristic of an intergranular crack. (Nomani, J., Pramanik, A., Hilditch, T., Littlefair, G., 2016)

The purpose of the present study is to investigate the initiation and growth of fatigue cracks in duplex steels. The scope of the study is to track the growth of the crack in its three dimensions in a high-cycle fatigue in the range of $10^{6}-10^{7}$ cycles. To achieve this objective, 10 samples of duplex steel SAF 2507 were cut by a laser machine. In order to do so, the method of cutting was chosen because of the pinpoint accuracy of the process. Previous studies (Георгиев Г., 2016; Tofique, M., 2014; Georgiev G., Argirov Y., Dimitrov D., 2018; Георгиев Г., Аргиров Я., Мечкарова Т., Антонов Г., 2017) have shown that the upper limit of sample destruction is close to 1000000 cycles at a load of $480 \mathrm{MPa}$ and about 5000 000 cycles at $460 \mathrm{MPa}$, a load of $460 \mathrm{MPa}$ selected.

Using the capabilities of 3D modeling software SolidWorks and AutoCAD, real processes are virtually simulated, which, in turn, allows for the tendency for the initiation and growth of a fatigue crack to 
be determined (Tonkovic Z., 2011; Heyder M., 2005). The results obtained are then used to predict the physical endurance of similar materials that are working in similar conditions.

\section{Object of research}

Given the capabilities of the equipment used to conduct the experiment, it was agreed that samples with a length of 10 to $20 \mathrm{~cm}$ would be most appropriate. The equipment's most appropriate and stable mode of operation is at a frequency of 50 to 80 hertz. The samples are cut from sheets of steel SAF2507 with a thickness of $3 \mathrm{~mm}$. To meet the above parameters, the geometry of the sample was calculated using Solidworks3D software. The required frequency range of the sample was achieved, by conducting various experiments with different mass and geometry of the sample. From the geometric shape thus acquired, the actual sample is obtained by cutting the sheet material with a laser machine. Figure 1.

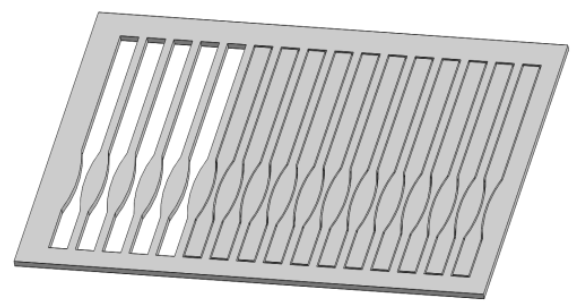

Fig. 1. Cutting samples using a laser machine.

The method of cutting is chosen for practical purposes, on accounts of its small area of thermal influence and minimal, if any, structural changes. This effect is achieved by setting, through numerous experiments, the optimal mode of cutting. The resulting sample is subject to further processing, including grinding and polishing the specimen surface.

Thus, the sample acquires the dimensions shown in figure 2 and table 1.

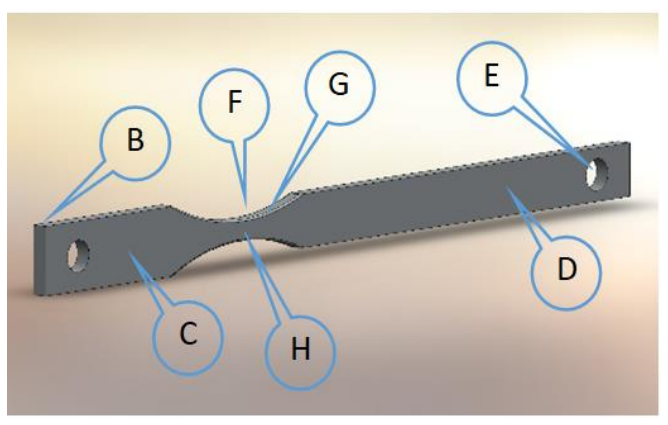

Fig. 2. Geometrical shape of the samples.

Table 1. Dimensions of the samples.

\begin{tabular}{|l|c|}
\hline \multicolumn{2}{|c|}{ sample dimensions, mm } \\
\hline Length & 160 \\
\hline Height & 3 \\
\hline Width of the gripped part & 13 \\
\hline Width in the free part & 10 \\
\hline Openings & $\Phi 6$ \\
\hline Curvature radius & $\mathrm{R} \mathrm{45}$ \\
\hline filet & $\mathrm{R} 0,37$ \\
\hline Smallest cross-section & $4 \times 3$ \\
\hline
\end{tabular}

Based on the effectiveness of many studies in the field and the acquired practical experience (Chirikov A., 2015; Argirov J., 2016; Аргиров Я., 2012), a conclusion is reached as to the crucial importance and significant impact of the curvature radii in the area of stress for the fatigue resistance of 
the sample. Further attention is paid to the smaller section of the work area displayed in Figure 3, where a crack is expected to occur during the work process. An essential requirement for this area, is to curve the residual sharp edges, left after laser resurfacing, to a curvature radius of up to $1 \mathrm{~mm}$. The sharp edges are removed using sandpaper from P100 up to P2000 in succession.

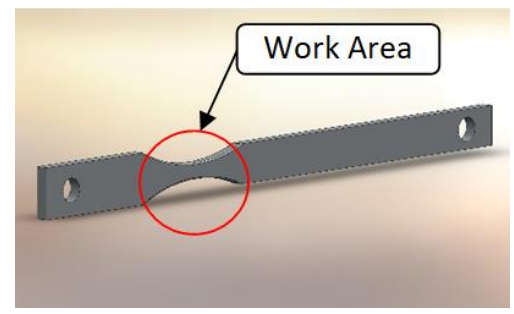

Fig. 3. Work Area.

\section{Fatigue test setup}

The samples are firmly fixed in a special tice made for the specific vibrating table (shaker). If the bolts are not sufficiently tightened, during the process of operation they will start to unscrew from the vibration forces, which causes the acceleration sensor to generate incorrect data. The cables of the acceleration sensor must be carefully fitted so that they do not come in contact with the sample. A specially selected frequency is used commensurate with the size of the sample. The amplitude of stress is determined in line with the selected step from the experimentation plan. The software provides the ability to determine the crack formation moment, which is normally visible only at high magnification. Figure 4

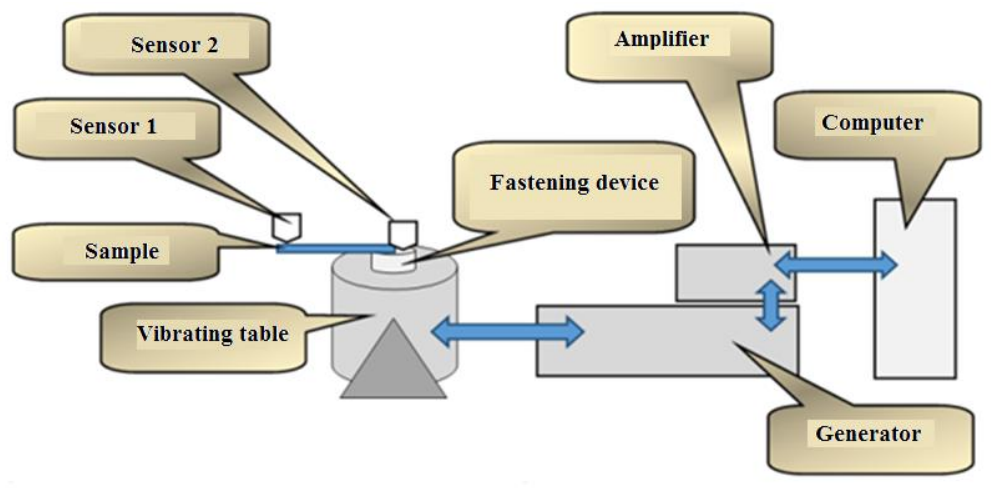

Fig. 4. Fatigue experimental equipment.

\section{Experimental procedure}

\subsection{Cyclical fatigue on a vibrating table (shaker)}

On the experimental equipment shown in figure 4 , we attach the sample according to the described procedure. Then, cyclical stress is applied on the sample, observing the previously specified values for the amplitude and frequency. The process is monitored until an indication is provided by the software managing the setup. The indication signals the formation of a focus (micro-crack). After the formation of a focus, the growth of the crack is monitored. This crack is not visible even at very high magnifications. Even using a deep penetrating penetrant, it is still not possible to detect the crack due to its minute width. It is precisely for this reason why the penetrant is only used to mark the growth of the crack during the fatigue test. During the testing, the sample experiences tensile stresses, increasing the width of the crack, thus the penetrant penetrates into the flaw, providing visual data on its extensive growth. Figure 5. 


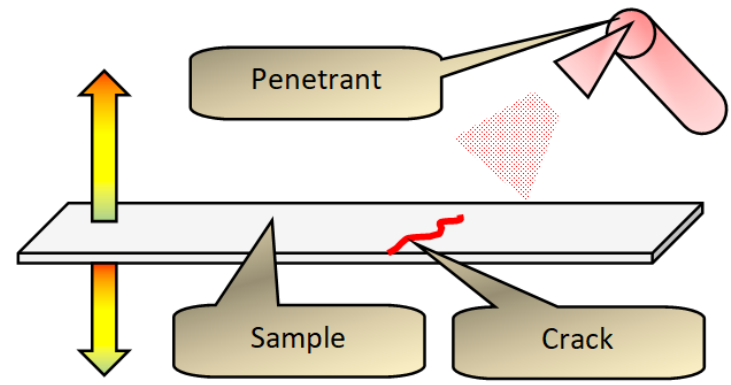

Fig. 5. Sequence for determining the growth of cracks.

After reaching the desired length of the crack, the sample is taken out of the fatigue experimental equipment. Using a macrostructural analysis we determine the length of the crack in both directions. The procedure is repeated several times, using a stereo microscope for macrostructural examination to monitor the growth of the crack in both directions.

To determine how accurate the radii of curvature in the cross-section are, the samples are cut crosswise at the end of the working area, at a sufficient distance from the crack before performing a layerby -layer analysis. The part of the sample that is close to the crack but not affected by it is used to determine the radii. Fixing the sample in clamps and using sandpaper with grit sizes of P100 to P2000 in succession, allows for a sufficient amount of pictures to be taken in order to obtain an accurate image of the cross-section. A stereomicroscope is used to capture the image and a scale ruler is used to measure the exact dimensions. The curvature radii are determined with the help of a scale ruler and the images of the sample are created by using the tools of the software Solidworks 3D and AutoCAD. The measurement is performed as a means to ascertain the optimal radius of curvature which should be between $0.2 \mathrm{~mm}$ and $1 \mathrm{~mm}$ for the specified geometrical shape, as illustrated in figure 6 and figure 7 .

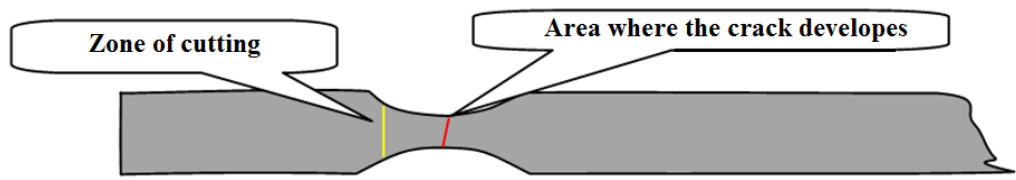

Fig.6. Area of cutting to determine the curvature radius.

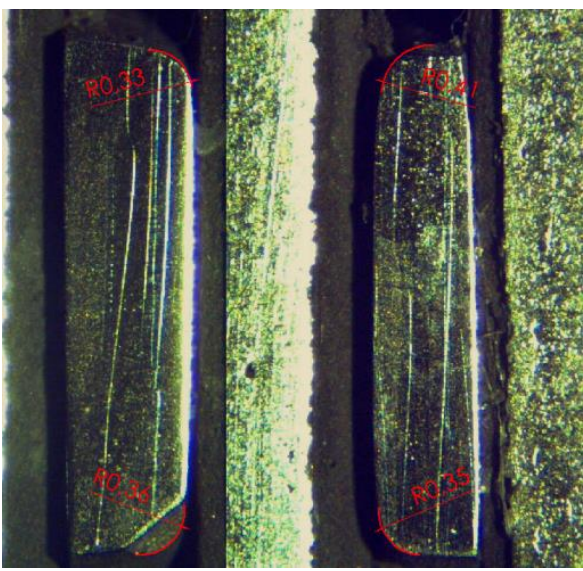

Fig. 7. Measuring the radius.

In order to investigate the growth of the fatigue crack, a microstructural analysis was carried out and use was made of a metallographic microscope with magnification of x100 and x1000. The microscopic image depicts vividly the growth of a fatigue crack between the grains in the structure. The microstructure of the fatigue crack is clearly visible in the figure below. 


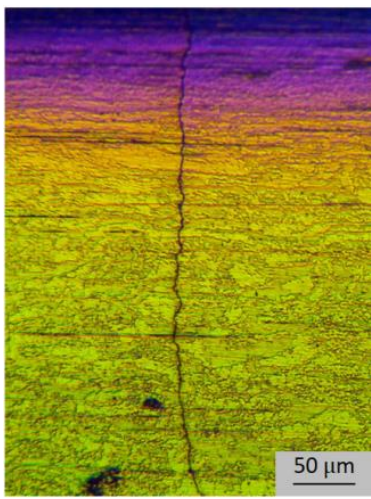

x 100

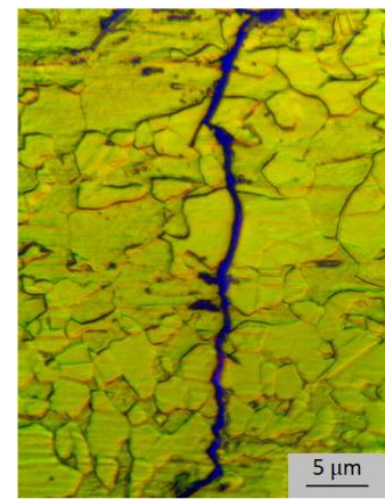

$\mathrm{x} 1000$

Fig. 8. Microstructure of fatigue crack.

\subsection{Layer by layer analysis}

A bench grinder is used to remove the required layer of material, ranging mostly from 0.1 to $0.3 \mathrm{~mm}$, whereupon sandpaper with grit sizes P100 to P2000 is applied in succession. The procedure is repeated at least seven times or until the deepest layer with a crack is reached. The stripped material is measured using an indicator clock with an accuracy of 0.001 at two points in the narrowed zone - 1 and 2. Figure 9.

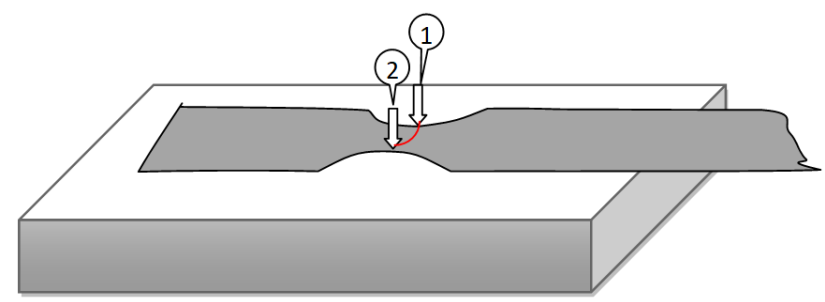

Fig. 9. Points of determining the width of the removed layer.

A picture is taken of the crack for each removed layer using a microscope with a magnification of 25 times. All pictures must capture the image in such a way that it is possible to accurately determine the position of the crack. To that effect, the picture is constructed in such a way that would distinctly indicate the two curvatures with a radius of R45. The images are processed using Solidworks 3D, each having R45 curvature and the crack being layered for each layer. Thus layered, they show the expansion of the crack in both directions. Figure 10. Solidworks is used to visualize the cracks. The layer- by- layer analysis aims to obtain the relief of the growth of the crack.

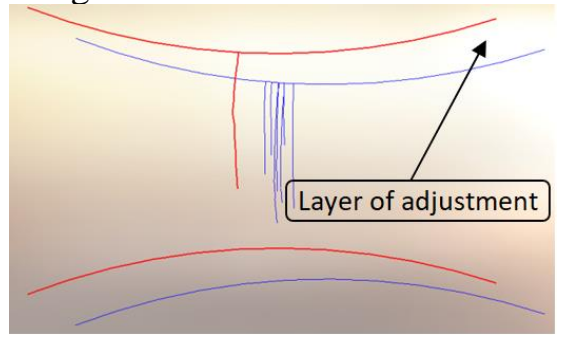

Fig. 10. Creating a profile of the motion of the crack.

\subsection{SolidWorks 3D - visualization of the cracks}

SolidWorks 3D is used to visualize the profile of the crack. The data from table 2 is used where each layer is displayed on a different surface. The distances between each layer are accurately kept. Using the connect layers tool, all points are connected in a 3D environment. The tool creates a 3D profile with a smooth transition between the different points. Disclosed in Figures 11 and 12 are the 3D profiles of the crack patterns produced in samples 1 and 2 , respectively. 


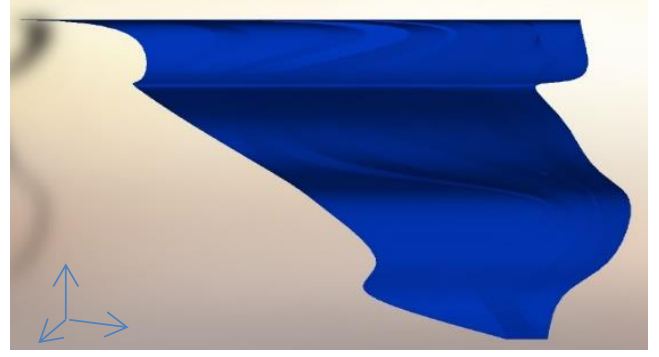

Fig. 11. 3D depiction of crack of sample 1

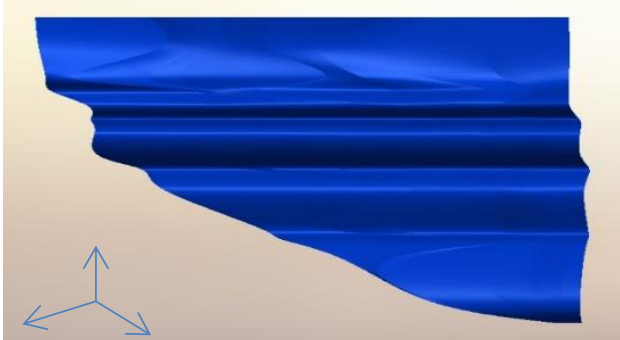

Fig. 12. 3D depiction of crack of sample 2

\section{Results and discussion}

\subsection{Results of the layer by layer analysis}

The results are divided in two groups. In the first group the samples gathered are with cracks that have developed to the end of the surface area of the sample and in the other group, the cracks have ran up to $2 / 3$ of the surface area. One sample out of each group is chosen to visualize the front of the crack. The points at each end of the narrowed part are measured.

Table 2. Results of the layer by layer analysis for samples 1 and 2 .

\begin{tabular}{|c|c|c|c|c|}
\hline \multirow{11}{*}{ 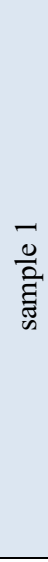 } & $\begin{array}{l}\text { section depth } \\
\text { zone } 1 / \text { zone } 2 \\
{[\mathrm{~mm}]}\end{array}$ & $\begin{array}{l}\text { crack } \\
\text { length } \\
{[\mathrm{mm}]}\end{array}$ & $\begin{array}{l}\text { fatigue } \\
\text { cycle/ } \\
\text { stress } \\
{[\mathrm{N}] /[\mathrm{MPa}]}\end{array}$ & $\begin{array}{l}\text { radius of } \\
\text { curvature } \\
{[\mathrm{mm}]}\end{array}$ \\
\hline & $0 / 0$ & 3,4 & \multirow{10}{*}{$\begin{array}{l}\frac{P}{+} \\
\frac{1}{8} \\
8 \\
8 \\
8 \\
8 \\
i\end{array}$} & \multirow[b]{2}{*}{$\mathrm{R} 10,38$} \\
\hline & $0.313 / 0.116$ & 2,8 & & \\
\hline & $0.372 / 0.24$ & 2,92 & & \multirow[b]{2}{*}{$\mathrm{R} 20,33$} \\
\hline & $0.777 / 0.552$ & 2,96 & & \\
\hline & $0.821 / 0.637$ & 2,61 & & \multirow{2}{*}{$\begin{array}{l}\text { crack start } \\
\text { R30,31 }\end{array}$} \\
\hline & $1.107 / 0.965$ & 2,6 & & \\
\hline & $1.281 / 1.136$ & 2,3 & & \multirow{4}{*}{$\mathrm{R} 40,39$} \\
\hline & $1.716 / 1.466$ & 2,2 & & \\
\hline & $2.014 / 1.797$ & 1,55 & & \\
\hline & $2.208 / 2.015$ & 1,35 & & \\
\hline
\end{tabular}

\begin{tabular}{|c|c|c|c|c|}
\hline \multirow{11}{*}{ 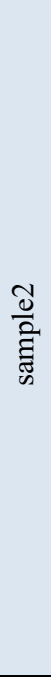 } & $\begin{array}{l}\text { section depth } \\
\text { zone 1/ zone2 } \\
{[\mathrm{mm}]}\end{array}$ & $\begin{array}{l}\text { crack } \\
\text { length } \\
{[\mathrm{mm}]}\end{array}$ & $\begin{array}{l}\text { fatigue } \\
\text { cycle/ } \\
\text { stress } \\
{[\mathrm{N}] /[\mathrm{MPa}]}\end{array}$ & $\begin{array}{l}\text { radius of } \\
\text { curvature } \\
{[\mathrm{mm}]}\end{array}$ \\
\hline & $0 / 3.252$ & 2,79 & \multirow{10}{*}{$\begin{array}{l}\stackrel{8}{+} \\
\frac{7}{8} \\
8 \\
8 \\
8 \\
8 \\
\text { i } \\
\text { in }\end{array}$} & \multirow[b]{2}{*}{$\mathrm{R} 10,37$} \\
\hline & $0.366 / 0.312$ & 2,3 & & \\
\hline & $0.547 / 0.519$ & 2,38 & & \multirow[b]{2}{*}{ R20,35 } \\
\hline & $0.685 / 0.639$ & 2,3 & & \\
\hline & $1.090 / 1.011$ & 2,3 & & \multirow{2}{*}{$\begin{array}{l}\text { crack start } \\
\text { R30,32 }\end{array}$} \\
\hline & $1.439 / 1.253$ & 2,17 & & \\
\hline & $1.627 / 1.466$ & 1,67 & & \multirow{4}{*}{$\mathrm{R} 40,41$} \\
\hline & $1.720 / 1.592$ & 1,56 & & \\
\hline & $1.877 / 1.714$ & 1,34 & & \\
\hline & $2.159 / 2.048$ & 0,85 & & \\
\hline
\end{tabular}

\subsection{Computer processing and analysis of results - Cross section of sample 1}

In sample 1 cross-section surface, the crack has developed to the end of the narrow section. Here the crack runs deeply throughout the entire length of the no stress line. The length of the crack in the longitudinal section is $80 \%$ of the height of the section. The area of the crack is $44 \%$ of the area of the cross section. Figure 13. 

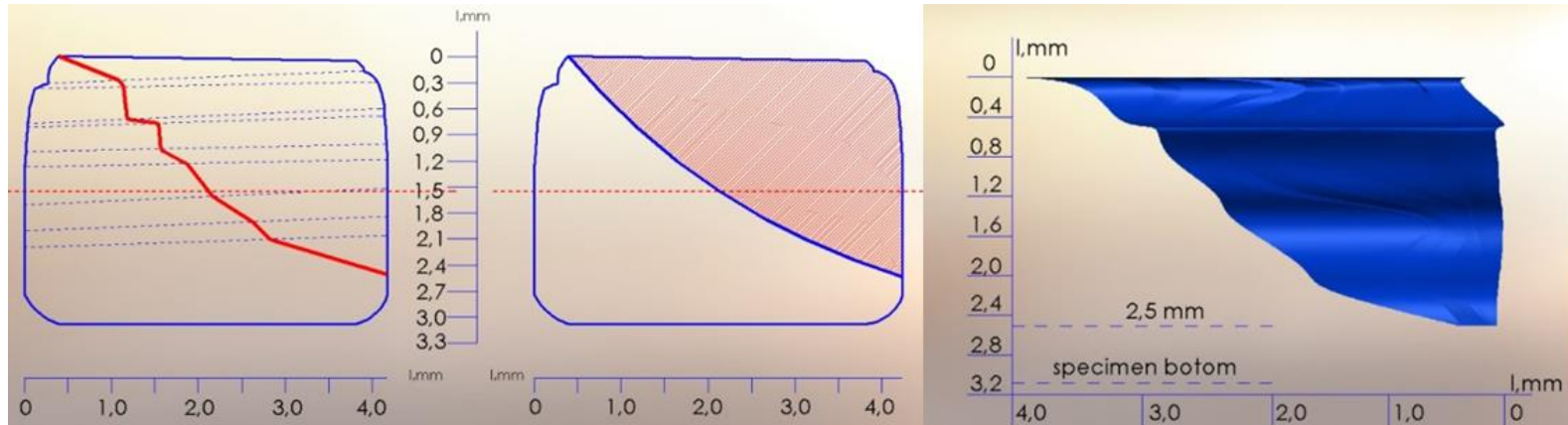

Fig.13. Growth of the crack of sample 1 in a cross section.

\section{- Cross section of sample 2}

In sample 2 cross section surface, the crack growth is $70 \%$ of the narrow part. Here again the crack has developed deep down within the depths of the no stress line. The length of the crack in the longitudinal section is $70 \%$ of the height of the section. The area of the crack is $32 \%$ of the area of the cross section. Figure 14.
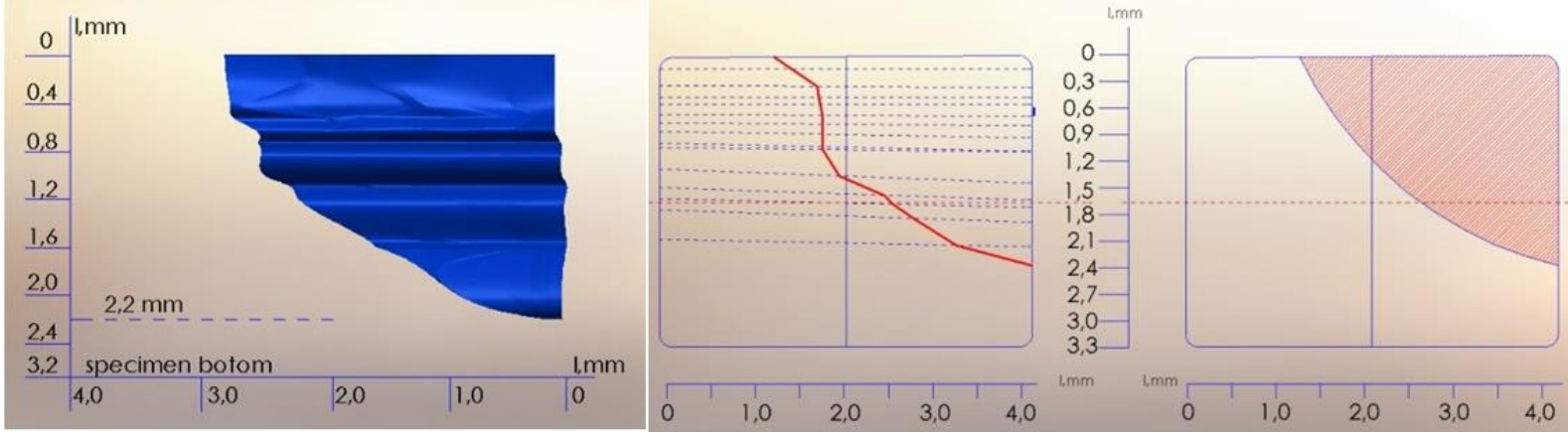

Fig. 14. Growth of the crack of sample 2 in a cross section

\section{- Longitudinal section of sample 1 and 2}

Observed, in sample 1, is a shift of the surface crack of $0.28 \mathrm{~mm}$ from the initial point. In a depth of $0.5 \mathrm{~mm}$, a $0,5 \mathrm{~mm}$ displacement of the crack is considered relative to its surface displacement. At a depth of $2,5 \mathrm{~mm}$, the displacement is $0,46 \mathrm{~mm}$. The crack has a zigzag profile of growth and the displacement is in the direction of the vibrating table's (shaker) grip. The total width of the front in a longitudinal section is $0,73 \mathrm{~mm}$. The crack has an incline of $10.4^{\circ}$. Figure 15.

In sample 2 we observe a shift of the surface crack of $0.06 \mathrm{~mm}$ from the initial point. In a depth of $0.9 \mathrm{~mm}$, a $0,22 \mathrm{~mm}$ displacement of the crack is regarded relative to its surface displacement. At a depth of $2,2 \mathrm{~mm}$, the displacement is $0,26 \mathrm{~mm}$. The crack has a poorly expressed zigzag profile of growth and the displacement is away from the heat affected zone at vibrating table (shaker). The total width of the front in a longitudinal section is $0,43 \mathrm{~mm}$. The crack has an incline of $6,75^{\circ}$. Figure 15 . 


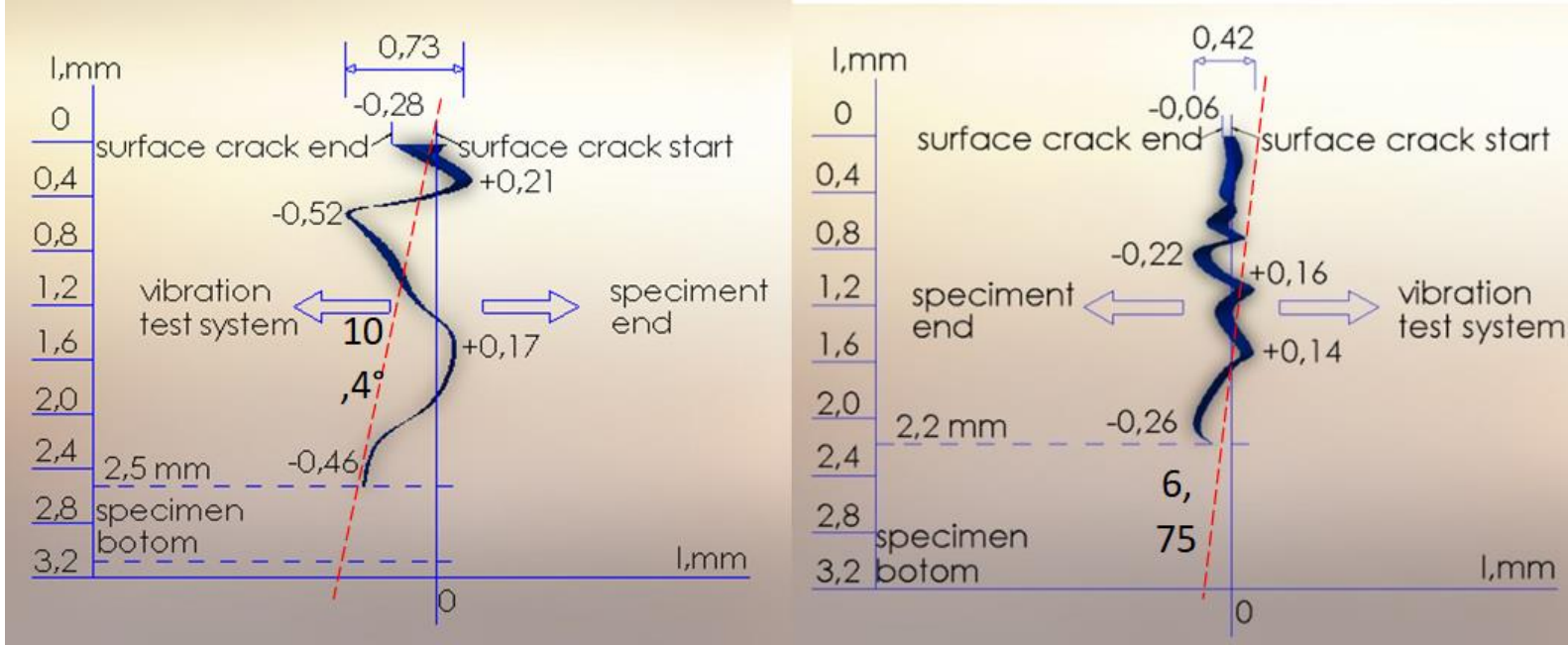

Fig.15. Growth of the crack in a longitudinal section of sample 1 and 2

\subsection{Comparison of sample 1 and 2}

The similarity in the growth of the crack front segment is discernible in the cross section itself. The growing of the cracks is visually represented in Figure 16 and marked in red for sample 1 occurring at a similar angle of $46^{\circ}$ and in blue for sample 2 -at $52^{\circ}$.

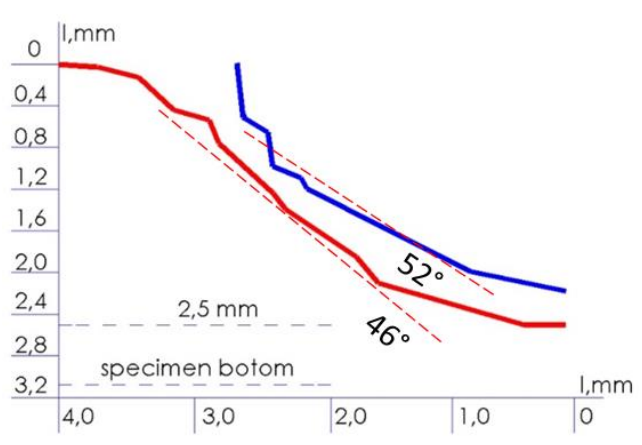

Fig. 16. Comparison of the cracks in a cross section.

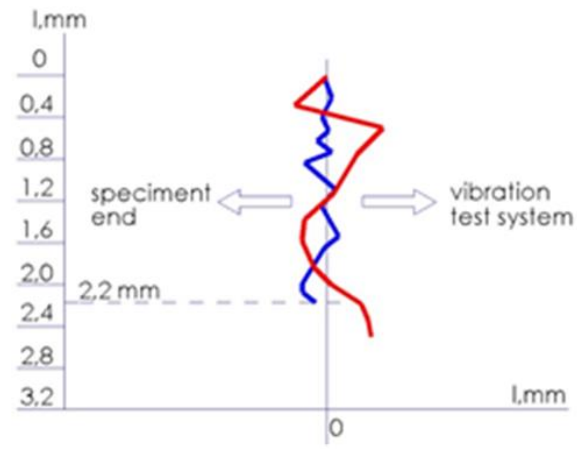

Fig. 17. Comparison of the cracks in a longitudinal section.

In the cross-section, there arise a noticeable difference between the two stages of the propogation of the crack growth. With the increase in the crack's length, an increase in its width is observed. There is no evidence that the vibrating table (shaker) has any effect on the longitudinal section of the crack. There is no clear direction of the crack towards or away from the vibrating table (shaker), leading to varied and inconsistent results . Figure 17.

With the help of a deep penetrating penetrant, a few points are visually determined. Upon the crack reaching about $10 \%, 30 \%, 50 \%, 70 \%, 100 \%$, relevant pictures of the cross and longitudinal section have been taken by the stereomicroscope and the obtained data was duly registered in table3.The propagation of the crack growth occurs in the way pictured in figure 16. Clearly, after a focus is formed, the crack grows in both directions uniformly, in the same manner. As step 30\% passes, the longitudinal growth gets slower relative to the cross growth. The longitudinal growth of the crack increases by $3 \%$, allowing for the cross-sectional crack growth to extend with $20 \%$. This growth continues for the rest of the development of the crack. Figure 18. 
Table 3. Results of the observation

\begin{tabular}{|c|c|c|c|}
\hline \multirow{6}{*}{ 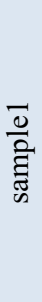 } & step & \begin{tabular}{|l|} 
crack \\
length \\
mm \\
\end{tabular} & $\begin{array}{l}\text { section } \\
\text { depth mm }\end{array}$ \\
\hline & $10 \%$ & 0,45 & 0,4 \\
\hline & $30 \%$ & 1,23 & 1,5 \\
\hline & $50 \%$ & 2,21 & 1,6 \\
\hline & $70 \%$ & 2,96 & 1,7 \\
\hline & $100 \%$ & 3,81 & 1,9 \\
\hline
\end{tabular}

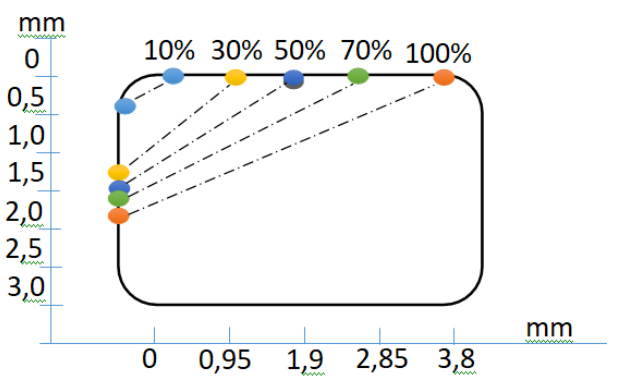

Fig. 18. Comparison Visualization of the crack growth in two directions

\section{Conclusions}

Radii between R0.30 and $0.50 \mathrm{~mm}$ reduce the accumulation of stress and do not affect the durability of the material significantly. Smaller radii, however, result in a greater reduction in durability.

The sharp distinction between the two stages of the crack growth is easily visible. As the length of the crack increases, so does its width. Undoubtedly, there seems to be no evidence as to the overall effect of the vibrating table (shaker) on the longitudinal growth of the crack. Moreover, there is no apparent growth of the crack, either towards or away from the vibrating table (shaker). All in all, the results from the observations regarding the direction of the crack are varied.

In microstructural terms, it appears that the movement of the crack has a pronounced intercrystallite character. Multiple branches indicate that the crack reduces its energy by spreading repeatedly as it develops.

The research findings advanced hereto prove equally applicable to the machine elements used predominantly in the chemical industry and, indisputably, in a number of other sectors of manufacturing as well.

\section{References}

Аргиров, Я., Стоянова А., Мечкарова Т. (2012). Изследване влиянието на неметалните включвания в материала при уморно разрушаване на сондажен вал. Трети международен научен конгрес, 50 години Технически Университет - Варна, 8, 29-34.

Георгиев Г. (2016). Влияние на структурата върху разпространението на пукнатини в зоната близка до прага на разпространение. Известия на съюза на учените - Варна. Серия "Технически науки" 1, стр.65.

Георгиев Г., Аргиров Я., Мечкарова Т., Антонов Г. (2017). Моделиране на уморната якост на валработно колело от центробежна помпа изработени от дуплексна стомана SAF2507. Дни на безразрушителния контрол 2017, 1, 254-257

Argirov, J., Yankova R. \& Antonov G. (2016). Study Fatigue in Materials of Drill Pipes. TEM JOURNAL, ISSN 2217-8309. 5(1), 50-55.

Chirikov, V., Dimitrov D. \& Kostov K. (2015). Universal experimental relation for natural friquencies of transversal vibration of stubby free-free beams, Diagnostics, Resource and Mechanics of materials and structures, 4, 42-51. https://doi.org/10.17804/2410-9908.2015.4.042-051

Georgiev G., Argirov Y., Dimitrov D. (2018). Investigation of the fatigue strength and development of cracks in duplex steel 2507. International journal "NTD days", 1(4), 520-525 
Heyder, M., Kolk, K., Kuhn, G. (2005). Numerical and experimental investigations of in the influence of corner singularities on 3D fatigue crack propagation. Engineering Fracture Mechanics (72) 2 095-2 105. https://doi.org/10.1016/j.engfracmech.2005.01.006

Nicholls, J. (1993). AB Sandvik Steel, Duplex Stainless Steels for Demanding Applications. Paper presented on the 12th International Corrosion Congress in Houston, Texas.

Nomani, J., Pramanik, A., Hilditch, T., \& Littlefair, G. (2016). Investigation on the behaviour of austenite and ferrite phases at stagnation region in the turning of duplex stainless steel alloys. Metallurgical and materials transactions, 47(6), 3165-3177. https://doi.org/10.1007/s11661-016$3472-0$

Slavov, S., and Dimitrov, D. (2016). Experimental research of the effect of the regular shaped roughness formed by using new kinematical scheme for surface plastic deformation process on the number of cycles to fatigue failure of stainless steel 3041 (cr18ni8). ESU Евразийский союз ученых 42, 11-22. Google Scholar

Tofique, M. (2014). Very high cycle fatigue of duplex stainless steels and stress intensity calculations. Licentiate thesis - Karlstad University Studies.

Tonkovic, Z., \& Aliabadi, F., (2011) Fatigue Crack Shape Prediction Based on the Stress Singularity Exponent. Key Engineering Materials, Advances in Fracture and Damage Mechanics, 2011, 178-181. https://doi.org/10.4028/www.scientific.net/KEM.488-489.178 